\title{
Moral Reasoning and Political Leader Preference of Senior High School Students of a Private School
}

\author{
Raymond P. Goyon ${ }^{1}$ and Carlos Eduardo I. Legaspi ${ }^{2}$ \\ ${ }^{1}$ Colegio de Sta. Ana de Victorias, Inc., Victorias City, Philippines \\ ${ }^{2}$ University of Negros Occidental-Recoletos, Bacolod City, Philippines
}

\begin{tabular}{l} 
Article history \\
Submitted: 22 October 2020 \\
Revised: 10 November 2020 \\
Accepted: 12 November 2020 \\
\hline Keywords \\
Social Science \\
Education \\
Moral Reasoning \\
Political Leaders' Preference \\
Senior High School Students \\
Private School \\
Victorias City
\end{tabular}

\section{Article history}

Revised: 10 November 2020

Keywords

Social Science

Moral Reasoning

Political Leaders' Preference

Private School

Victorias City
Introduction. Kohlberg's moral development theory focuses on the thinking process that occurs when one makes a moral decision. Kohlberg had identified three stages of moral development: Preconventional, Conventional, and post-conventional. Moral reasoning, as perceived to be a factor in the decision-making, is a rational act guided by moral principles. It is a subjective evaluation related to practical reasoning, where one justifies the idea based on how a person views various thing. Moreover, decisions rely on reasoning; moral reasoning is related to making a congruent decision when a person creates preference takes more courage in deciding whom to elect during elections. Voting preferences can be affected by certain factors such as influences of peers, media, family, and Church/religious community. Political leader preference is described as a judgment based on evaluations and observations through interaction with political content. It may also refer to a political or philosophical opinion on an individual pertained to be a candidate for leadership. Like the Senior High School (SHS) students, some new voters are easily swayed by some politicians. The purpose of this study is to determine the level of moral reasoning and the degree of preference for a political leader of SHS students when grouped according to sex, family monthly income, age, and church ministry involvement. Specifically, it also compares the degree of preference for political leaders when grouped according to variables and correlates moral reasoning and preference for political leaders. Likewise, it explores other factors that influence the political leaders' preference.

Methods. This study used the descriptive-correlational research design. In finding the level of moral reasoning and the degree of preference, descriptive analysis was used. For significant difference and relationship, correlational design and inferential analysis were used. The participants of the study were grade 11 students using stratified random sampling. Data were gathered using a researchermade questionnaire. The questionnaire underwent validation and reliability testing. Mean, Standard Deviation, frequency count, percentage distribution, Mann Whitney $U$ test, and Spearman rank correlation were used to analyze the data.

Results. The level of moral reasoning of the SHS students as a whole and when grouped according to age, sex, family monthly income, and church ministry involvement is post-conventional. Meanwhile, the degree of preference for a political leader as a whole and grouped according to the variables is very high. There is no significant difference in the degree of preferences for the SHS students' political leaders when they are grouped according to the mentioned variables. On the other hand, there is a significant difference in the degree of preferences when they are grouped according to sex; female students have higher results than male students. The overall assessment showed no significant relationship between moral reasoning and the degree of preference for a political leader. Finally, family ranks first as influencer to political leaders' preference of students, followed by media, peer, and the church.

Conclusion. Senior high school students are at the post-conventional level, which is the highest in Kohlberg's stages of moral reasoning. Regardless of the variables, students have a similar preference in selecting for a political leader. This implies that students are very much aware of the possible effects of their decisions. Moreover, the absence of significant relationship between moral reasoning and political preference signifies that the preferences of students in terms of political leaders is is not 
associated with their moral reasoning. Instead, moral reasoning could just be one factor, a result of an influence, or an entirely different concept.

Practical Value of the Paper. The findings of the study are of considerable value to Social Science teachers in educating the students of the concepts of government, history, economics, and civic ideals, especially in exercising their rights to suffrage. Also, the Social Science coordinator may allocate a budget for students and teachers' training program. School administrators can implement a new way of educating students about voting. Finally, this research can be a useful reference for future researchers who would plan to make any related study focusing on the variables that are not part of this study.

\section{References}

Bautista, J. (2010). Church and state in the Philippines: tackling life issues in a culture of death. Sojourn: Journal of Social Issues in Southeast Asia, Vol. 25, No. 1, Religion and Politics in Southeast Asia (April 2010), pp. 29-53

Bernardo, A. (2017). Exploring the political values of Filipinos using an etic approach. The University of Macau. https:// www.pap.org.ph/sites/default/files/upload/pjp2017-50-2-pp7-38-bernardo-exploring_political_values_of_ filipinos_using_an_etic_approach.pdf

Coppin, G., Delplanque, S., Cayeux, I., Porcherot C., \& Sander, D. (2010). I am no longer torn after choice: how explicit choices implicitly shape preferences of odors. March 5, 2010. Retrieve from https:// doi. org/10.1177/0956797610364115

Fumagalli, M., Ferrucci, R., Mameli, F., Marceglia, S., Mrakic-Sposta, S., Zago, S., \& Lucchiari, C. (2009). Gender-related differences in moral judgments. Retrieved from PMID: 19727878 DOI: 10.1007/s10339-009-0335-2

Garrigan, B., Adlamb, A. \& Langdonc, P. (2018). Moral decision-making and moral development: Toward an integrative framework. Retrieved from: doi.org/10.1016/j.dr.2018.06.001

Hansson, A. P. H. (2017). At the end of the road? On differences between women and men in leadership behavior. Leadership and Organization Development Journal. 32 (5): 428-441. doi:10.1108/01437731111146550.

Murcia, J. V., \& Guerrero, F. (2016). Characterizing political cynicism of first-time voters for the 2016 Philippine elections. Retrieved from http://dx.doi.org/10.2139/ssrn.2876985

Richardson, H. (2018). Moral Reasoning. Retrieved from https://plato.stanford.edu/entries/reasoning-moral.

Sanders, C. (2020). Lawrence Kohlberg's stages of moral development psychology. SAGE publication's Encyclopedia of Human Development (2006), retrieved from https://www.britannica.com/science/Lawrence-Kohlbergsstages-of-moral-development

Vera-Estay E., J.J. Dooley \& M.H. Beauchamp (2015) Cognitive underpinnings of moral reasoning in adolescence: The contribution of executive functions. Journal of Moral Education, 44:1, 17-33, DOI: 10.1080/03057240.2014.986077

\section{Correspondence:}

Raymond P. Goyon [rgoyon83@gmail.com]

https://orcid.org/0000-0002-3400-0223 